\title{
Allergic Reaction to Peripheral Nerve Stimulator
}

\author{
Linqiu Zhou ${ }^{1,2, *}$, Anthony Lee ${ }^{3}$, Robin Schaffner ${ }^{2}$ and Gerald Dworkin ${ }^{4}$ \\ ${ }^{1}$ Department of Rehabilitation Medicine, Jefferson Medical College, Thomas Jefferson University, Philadelphia, PA \\ 19107, USA \\ ${ }^{2}$ Woodbury Spine, 730 North Brand Street, Suit 205, Woodbury, NJ, 08096, USA \\ ${ }^{3}$ Southwest Sport and Spine, Scottsdale, AZ 85258, USA \\ ${ }^{4}$ Department of Physical Medicine and Rehabilitation, Philadelphia College of Osteopathic Medicine, Philadelphia, PA \\ 19131
}

\begin{abstract}
Objective: Pain physicians should be aware of a rare but possible complication associated with the use of peripheral nerve stimulation. While pacemaker dermatitis and allergic reactions to a spinal cord stimulator have been recognized, there have been no case studies of allergic reactions to a peripheral nerve stimulator described in the literature. Method: We presented a case report where the patient developed a post-operative allergic reaction. The symptoms reported were itching, a rash on the scalp, and a rash on the back of cervical and thoracic spine and buttocks, where the bilateral occipital peripheral nerve stimulator leads and pulse generator had been implanted for the patient's cervicogenic headache. Result: The patient experienced excellent relief of her headache and associated symptoms after stimulation therapy. However, she developed a skin reaction immediately after surgery and her symptoms gradually became severe and systemic. Conservative treatment and modalities failed to provide relief. Ultimately, her symptoms completely resolved after the device was removed. Conclusion: An individual with a history of a significant allergic disease may develop an allergic reaction to the components of the peripheral nerve stimulation device. The details of a ptatient's allergy history and a patch test of the nerve stimulator components are necessary in this group of patients before proceeding with peripheral nerve stimulation therapy. If the patient with an allergic reaction to the implanted device fails conservative therapy, then removal of the device should provide definitive treatment and relief of the allergy associated symptoms.
\end{abstract}

Keywords: Occipital nerve stimulation, chronic headache, cervicogenic headache, allergic reaction, Spinal cord stimulation, Peripheral nerve stimulation.

\section{CASE REPORT}

This case report discusses a 54-year-old woman with a chief complaint of left-sided dominant headaches for 2 years following trauma to her head with resultant anterior cervical fusion. She described the headache as constant and originating in the neck radiating to the left occipital and parietal areas. There was occasional radiation to the right side. She denied shifting of the pain to the opposite side and stated the pain was aggravated by range of motion of the cervical spine. Pharmacologic interventions provided minimal short term relief and a physical therapy program provided no relief.

A diagnosis of cervicogenic headache was made and was further confirmed after the patient received complete relief following anesthetic block of the occipital nerve [1]. After the return of her headache, she underwent anesthetic blocks of the C1/2 and C2/3 facet joints and branches of the C2 (the greater occipital nerve) and C3 spinal rami (the lesser and

*Address correspondence to this author at the 730 North Broad Street, Suite 205, Woodbury, New Jersey 08096, USA; Tel: 856-202-5331 (0)

Fax: 856-202-5638; E-mail: linzhoumd@yahoo.com third occipital nerves), which provided 4 weeks of pain relief [2]. During these 4 weeks in which time she did not experience left sided headaches, she experienced a right sided headache, which was relieved by a right sided occipital nerve block. The decision was then made to proceed with a bilateral occipital nerve stimulator trial, which would provide long-lasting pain relief. Following the successful trial, the patient underwent permanent implantation of Medtronic occipital nerve stimulators. The procedure was performed under general anesthesia. After appropriate skin prep, a "T" shape incision was made below the occipital protuberance until the deep fascia was exposed. Then a pre-bended 15Gauge spinal needle was inserted subcutaneously from the incision toward the lateral occipital. After an 8-contact spinal cord stimulation lead was inserted, the spinal needle was removed. The second lead was then inserted with the same technique. These leads were anchored to the deep fascia and then tunneled to the back of the thoracic region, where they were connected to two extension leads. These extension leads were tunneled to the right buttock and connected to a pulse generator. The stimulation provided complete resolution of her headache (Fig. 1). Immediately after the surgery, the patient noted intense itching of her scalp and the back of 
her neck, where the leads had been implanted. Her symptoms were relieved by Benadryl. The patient then recalled that she has a history of a skin reaction to adhesive tape which triggers bronchial asthma and allergic rhinitis. She also has a history of allergies to aspirin, penicillin and morphine, which were associated with hives and asthma. She denied sensitivity to metal and rubber and has no history of autonomic dysfunction. On post-op day 8, she developed skin rash, swelling and severe pruritus at the area of the skin encompassing the lead and battery. After removal of the dressing/tapes and Nylon sutures (occipital incision), the

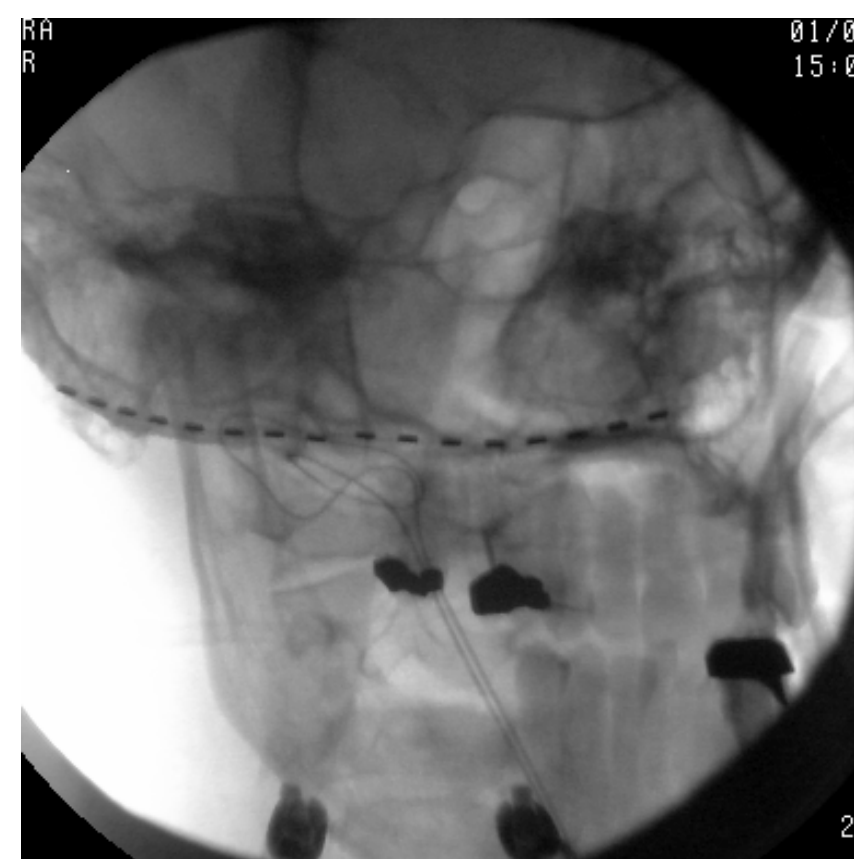

Fig. (1). Status-post bilateral occipital peripheral nerve stimulator implantation.

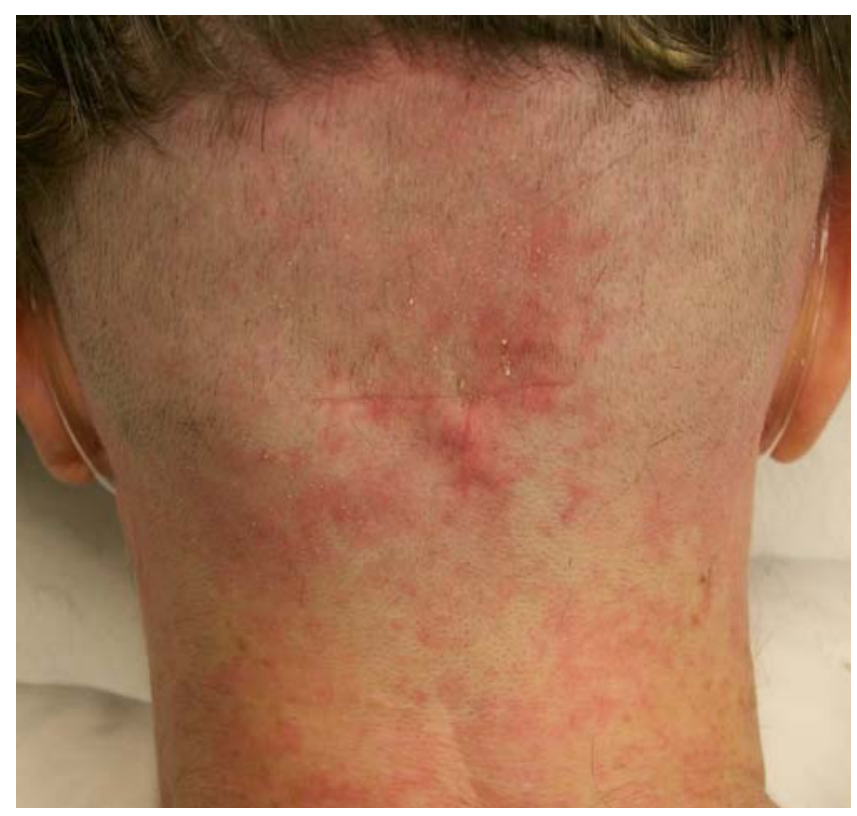

Fig. (2). Allergic reaction following bilateral occipital peripheral nerve stimulator implantation. incisions were carefully inspected. There was mild redness and swelling and there were no signs of infection or hematoma (Fig. 2).

Blood tests were conducted to include a blood culture, CBC with differential/platelet, metabolic panel, ESR, Creactive protein (IgE was not tested). The results were unremarkable. Her symptoms were aggravated by turning on the device or increasing the voltage of the stimulation; and were relieved by turning off the stimulation, antihistamines (Benadryl, Claritin Singulair), and topical corticosteroids. The patient was consulted by an immunologist. She then underwent patch testing to the components of the spinal cord stimulation parts, which was provided by Medtronic Company. The skin tests of silicone rubber MDX-70 and MED 7717 were positive at the first 24 hours and the skin reaction resolved in 48 hours. The final results returned inconclusive. Her skin symptoms gradually spread to the other parts of her body. Her headache and allergic reactions became intolerable and were unreleased by conservative treatments. Three months after the implantation, the device was removed. During surgery, the tissues and device were carefully inspected. There were no signs of inflammation, infection, seroma, hematoma or granular tissue. There was no visual damage of the leads or battery either. The tissues from the scalp, thoracic spine and battery site were then sent for pathology and culture. The pathology report showed the suture granuloma and scar in the occipital and thoracic sites. There was also chronic inflammation at the battery site. The tissue cultures were negative. Her symptoms completely resolved after the removal of the device. After removal of the device, her headaches returned to the same degree as before implantation. At one year follow-up, she denies any other sequela.

\section{DISCUSSION}

Cervicogenic headache has been defined as a chronic hemicranial pain usually beginning in the subocciptal region and spreading anteriorly to the ipsilateral orbital, frontal, and temporal areas. The headache is typically of daily occurrence and dominant on one side, but may be bilateral [3]. The benefits of peripheral nerve stimulators and occipital nerve block have been well documented, including for the management of patients with cervicogenic headache [4]. However, insertion of these devices may lead to clinically observable complications in rare cases, including allergic reactions. A variety of manifestations to pacemaker components ranging from localized dermatitis [5] to generalized pruritus and development of erythematous plaques [6] have been well described in the literature. Numerous case reports have documented allergic reactions to a variety of the materials used in pacemakers including titanium [5], nickel [7], epoxy [8] and polyurethane [9] (Table 1), the material which covers the leads. While there does exist rare cases of allergic reactions to spinal cord stimulators $[10,11]$ (Table 2), to date there have been no reports of allergic reaction following implantation of a peripheral nerve stimulator. As infection is a much more common cause of inflammation following implantation of such devices, it should be thoroughly investigated before suspecting and evaluating an allergy. Manage- 
Table 1. Reported Cases of Pacemaker Associated Allergic Reactions

\begin{tabular}{|l|l|l|l|l|}
\hline \multicolumn{1}{|c|}{ Allergen } & \multicolumn{1}{|c|}{ Reference } & Presentation and Reaction & \multicolumn{1}{c|}{ Onset } & \multicolumn{1}{c|}{ Results of Patch Test } \\
\hline \hline Titanium & Peters MS, et al. [5] & $\begin{array}{l}\text { Localized dermatitis on } 4 \\
\text { occasions following pace- } \\
\text { maker implantation }\end{array}$ & 6 weeks - 17 months & $\begin{array}{l}\text { Positive for titanium and } \\
\text { nickel sulfate 2.5\% }\end{array}$ \\
\hline Nickel & Landwehr AJ, et al. [7] & $\begin{array}{l}\text { Acute pompholyx-like } \\
\text { eruption on both hands }\end{array}$ & 2 days & $\begin{array}{l}\text { Positive for nickel sulfate } \\
5 \%\end{array}$ \\
\hline Epoxy & Andersen KE, [8] & $\begin{array}{l}\text { Pain, swelling and discol- } \\
\text { oration of skin surrounding } \\
\text { pacemaker site }\end{array}$ & 9 months & $\begin{array}{l}\text { Positive for epoxy resin } \\
\text { hardener }\end{array}$ \\
\hline Polyurethane & Dery JP, et al. [9] & $\begin{array}{l}\text { Localized dermatitis and } \\
\text { pain over pacemaker site }\end{array}$ & 3 weeks & $\begin{array}{l}\text { Positive for polyurethane } \\
75 D\end{array}$ \\
\hline
\end{tabular}

Table 2. Reported Cases of Spinal Cord Stimulator Associated Allergic Reactions

\begin{tabular}{|l|l|l|l|l|}
\hline \multicolumn{1}{|c|}{ Allergen } & \multicolumn{1}{|c|}{ Reference } & Presentation and Reaction & \multicolumn{1}{c|}{ Onset } & \multicolumn{1}{c|}{ Results of Patch Test } \\
\hline \hline $\begin{array}{l}\text { Platinum, silicone, polyure- } \\
\text { thane }\end{array}$ & Ochani TD, et al. [10] & $\begin{array}{l}\text { Erythema and burning over } \\
\text { the tunneled leads, swelling } \\
\text { and hives }\end{array}$ & $\begin{array}{l}\text { 2 weeks } \\
\text { 4 weeks }\end{array}$ & $\begin{array}{l}\text { Positive for platinum, sili- } \\
\text { cone and polyurethane }\end{array}$ \\
\hline Nickel & McKenna KE, et al. [11] & $\begin{array}{l}\text { Localized dermatitis over } \\
\text { site of subcutaneous re- } \\
\text { ceiver }\end{array}$ & 1 month & Positive for nickel \\
\hline
\end{tabular}

ment of pacemaker or spinal cord stimulator reactions varies from control of local dermatitis with topical corticosteroids in mild cases to replacement of the device with one that is free of the causative allergen [12]. Replacement with customized devices consisting of non-allergenic materials such as silicone [13] and gold [14] has been demonstrated to resolve such reactions although the only complete treatment remains removal of all the identified allergens. In cases where an allergic reaction is suspected, it is important to obtain patch tests for all specific components of the device that was inserted. With the wide variety of materials that may be present within any device one must often rely on the manufacturer to provide the appropriate components. In our case, the results of skin patch testing provided by the manufacturer had shown that silicone rubber MDX-70 and MED 7717 were positive at the first 24 hours and the skin reaction resolved in 48 hours. However, the final results were inconclusive, although this does not necessarily eliminate contact allergy as a diagnosis [15]. Patients with a history of allergic disease are encouraged to undergo patch testing prior to device implantation to help guide the choice of device [16]. For the patient with confirmed diagnosis of cervicogenic headache and a history of allergic disease, radiofrequency neurolysis at the stem of the occipital nerve are recommended, while the duration of pain relief may last only 6-9 months [17].

\section{REFERENCES}

[1] Sjaastad O, Fredriksen T, Pfafferanth V. Cervicogenic headache: diagnostic criteria. The cervicogenic headache international study group. Headache 1998; 38: 442-5.
[2] Zhou L, Hud-Shakoor Z, Hennessey C, et al. Upper cervical facet joint and spinal rami blocks for the treatment of cervicogenic headache. Headache 2010; 50(4): 657-63.

[3] Bogduk N. The anatomy and pathophysiology of neck pain. Phys Med Rehabil Clin N Am 2003; 14: 455-72.

[4] Paemeleire K, Bartsch T. Occipital nerve stimulation for headache disorders. Neurotherapeutics 2010; 7(2): 213-9.

[5] Peters MS, Schroeter AL, van Hale HM, et al. Pacemaker contact sensitivity. Contact Dermatitis 1984; 11: 214-8.

[6] Romaguera C, Grimalt F. Pacemaker dermatitis. Contact Dermatitis 1981; 7: 333.

[7] Landwehr AJ, Van Ketel WG. Pompholyx after implantation of a nickel-containing pacemaker in a nickel allergic patient. Contact Dermatitis 1983; 9: 147.

[8] Andersen KE. Cutaneous reaction to an epoxy-coated pacemaker. Arch Dematol 1979; 115: 97-8.

[9] Dery JP, Gilbert M, O’Hara G, et al. Pacemaker contact sensitivity: case report and review of the literature. Pacing Clin Electrophysiol 2002; 25: 863-5.

[10] Ochani TD, Almirante J, Siddiqui A, et al. Allergic reaction to spinal cord stimulator. Clin J Pain 2000; 16: 178-80.

[11] McKenna KE, McCleane G. Dermatitis induced by a spinal cord stimulator implant. Contact Dermatitis 1999; 41: 229.

[12] Honari G, Ellis SG, Wilkoff BL, et al. Hypersensitivity reactions associated with endovascular devices. Contact Dermatitis 2008; 59: 7-22.

[13] Hayes DL, Loesl K. Pacemaker component allergy: case report and review of the literature. J Interv Card Electrophysiol 2002; 6: 2778.

[14] Syburra T, Schurr U, Rahn M, et al. Gold-coated pacemaker implantation after allergic reactions to pacemaker compounds. Europace 2009; 10: 1093.

[15] Maushagen E, Reichle B, Simon H. Circumscriptive erythema after implantation of a cardiac pacemaker. Z Kardiol 1994; 83: 340-2.

[16] Reed KB, Davis MDP, Nakamura K, et al. Retrospective evaluation of patch testing before or after metal device implantation. Arch Dermatol 2008; 144: 999-07. 
[17] Stovner LJ, Kolstad F, Helde G. Radiofrequency denervation of facet joints C2-C6 in cervicogenic headache: a randomized, dou- ble-blind, sham-controlled study. Cephalalgia 2004; 24(10): 82130

Received: February 19, 2012

Revised: April 11, 2012

Accepted: April 16, 2012

(C) Zhou et al.; Licensee Bentham Open.

This is an open access article licensed under the terms of the Creative Commons Attribution Non-Commercial License (http://creativecommons.org/licenses/by-nc/3.0/) which permits unrestricted, non-commercial use, distribution and reproduction in any medium, provided the work is properly cited. 